\title{
A STUDY OF SPLIT THICKNESS SKIN GRAFT TECHNIQUE IN STABLE ACRAL VITILIGO
}

\author{
Sankara Rao K1, D. Subba Rao 2, B. V. Ramachandra ${ }^{3}$, G. Srinivasulu4, N. B. Lakshmi ${ }^{5}$ \\ 1 Post Graduate Final Year, Department of Dermatology, Venereology \& Leprosy, Asram. \\ 2 Professor, Department of Dermatology, Venereology \& Leprosy, Asram. \\ 3 Professor \& HOD, Department of Dermatology, Venereology \& Leprosy, Asram. \\ ${ }^{4}$ Associate Professor, Department of Dermatology, Venereology \& Leprosy, Asram. \\ ${ }^{5}$ Assistant Professor, Department of Dermatology, Venereology \& Leprosy, Asram.
}

\begin{tabular}{l}
\hline ABSTRACT \\
\hline BACKGROUND \\
Different surgical techniques in the form of tissue or cellular grafting procedures are used alone or in combination with PUVA \\
sol therapy to treat stable vitiligo resistant to medical treatment.
\end{tabular}

\section{AIM}

To evaluate the cosmetic results obtained with split thickness skin grafts followed by PUVA sol therapy in stable acral vitiligo.

\section{METHODS}

Eighteen patients with stable acral vitiligo were treated with split thickness skin grafting and the patients were then put on PUVA sol therapy. The results obtained were analysed by the extent of repigmentation achieved as well as the final cosmetic outcome at the recipient site.

\section{RESULTS}

On objective assessment more than 75\% repigmentation was seen in 15 out of 18 patients with split thickness skin grafting followed by PUVA sol therapy.

\section{CONCLUSION}

Split thickness skin grafting when combined with PUVA sol therapy leads to better cosmetic outcome with faster onset of repigmentation in resistant stable acral vitiligo.

\section{KEYWORDS}

Split Thickness Skin Grafting, Donor Site, Recipient Site, Repigmentation.

HOW TO CITE THIS ARTICLE: Rao SK, Rao DS, Ramachandra BV, et al. A study of split thickness skin graft technique in stable acral vitiligo. J. Evolution Med. Dent. Sci. 2016;5(30):1581-1585, DOI: 10.14260/jemds/2016/372

\section{INTRODUCTION}

Vitiligo is a common acquired disorder of pigmentation that affects about $1 \%$ of the world population and spares almost no racial or ethnic groups. 1,2 It is resistant to conventional medical therapy in non-hairy areas of human body leading to great cosmetic disfigurement. ${ }^{3}$ This situation warrants surgical manoeuvre. There are many surgical procedures, among those split thickness skin grafting is a tissue grafting procedure which provides good, cosmetically acceptable results and not time consuming, cost effective procedure. ${ }^{4}$ Our present study deals with acral vitiligo, where the disease is very distressing.

\section{AIMS AND OBJECTIVES}

To evaluate the cosmetic results obtained with split thickness skin graft technique followed by PUVA sol therapy in stable acral vitiligo.

Financial or Other, Competing Interest: None.

Submission 25-02-2016, Peer Review 20-03-2016,

Acceptance 26-03-2016, Published 14-04-2016.

Corresponding Author:

Dr. Sankara Rao K,

Bharat Pet $3^{\text {rd }}$ Lane,

Door.No. 4/16/17

Amaravathi Road,

Guntur-522002.

Guntur Dist., Andhra Pradesh.

E-mail: shankarkunchala693b@gmail.com

DOI: $10.14260 /$ jemds $/ 2016 / 372$

\section{MATERIALS AND METHODS}

The study was conducted in the Department of Dermatology, Alluri Sitaramaraju Academy of Medical Sciences Hospital and College, Eluru, during the period from November $1^{\text {st }} 2013$ to October 31st 2015. Study group includes patients with acral vitiligo for more than 1 year and resistant to medical therapy. Total eighteen patients between 19-50 yrs. of age were included. Poor immune status of patient, chronic medical illness, bleeding diathesis, infection at the site, age below 12 years were excluded. In all these patients a complete history was taken including details of age at onset, duration of vitiligo, course of disease (Stable/progressive), associated conditions like thyroid disorders, diabetes mellitus, alopecia areata, perniciousanaemia, Addison's disease. Details of any previous treatment were noted. Our study - longitudinal interventional study.

\section{Criteria for Case Selection Inclusion Criteria}

- Patches should be stationary for at least 1 year.

- No new lesions since one year.

- Koebner's phenomenon should be absent.

\section{Exclusion Criteria}

- Bleeding diathesis.

- Infection at the site.

- Age below 12 years.

- Patients with HIV/HBsAg positivity.

- Keloidal tendency. 


\section{Preoperative Evaluation and Counselling}

Relevant investigations were done in all these patients like haemogram, fasting blood sugar, serum creatinine, serum TSH and urine examination for sugar, albumin, microscopy, HIV and HBsAg. In each case, the nature of the treatment was explained including benefits and side effects. Prior consent was taken.

\section{Preparation}

Both donor and recipient sites were cleaned, draped and infiltrated with local anaesthesia.

\section{Instruments Required}

Motor/manual dermabrader.

Straight artery forceps.

Sterilized razor blade.

Sterilized slides.

Tissue adhesive cyanoacrylate.

Tegaderm dressing.

\section{PROCEDURE}

\section{Donor Site}

A thin even split thin graft is obtained by razor blade held with straight artery forceps and transferred on to a slide, the graft taken should be $5 \mathrm{~mm}$ larger than the recipient site to avoid peripigmentary hollow.

\section{Recipient Site}

Recipient site is dermabraded with diamond burr attached to motor, till pinpoint bleeding points are seen. Then the graft placed on the dermabraded area. All patients were kept on oral antibiotics.

Followup
All patients were subjected to photochemotherapy from day 7 for a period of 3 months. Regular photographs were taken on every visit.

\section{RESULTS}

In present study out of (18) patients, (7) were male and (11) were female. Out of all cases females show significant clinical response as seen in Table 1 . All females were cosmetically conscious age group and their compliance and adherence to treatment schedule leads to significant response.Young adults of age between 20-40 years comprise majority of cases and same group also exhibits more than $(75 \%)$ repigmentation.

\begin{tabular}{|c|c|c|}
\hline Sex & $\begin{array}{c}\text { No. of Patients } \\
\text { Treated }\end{array}$ & $\begin{array}{c}\text { No. of Patients } \\
\text { Achieving }>\text { 75\% } \\
\text { Repigmentation }\end{array}$ \\
\hline Males & 7 & 4 \\
\hline Females & 11 & 11 \\
\hline \multicolumn{2}{|c|}{ Table 1: Sex wise Response }
\end{tabular}

The outcome of the surgery was evaluated in terms of percentage of area of repigmentation as seen in Table 2.

\begin{tabular}{|c|c|}
\hline $\begin{array}{c}\text { Degree of } \\
\text { Repigmentation }\end{array}$ & $\begin{array}{c}\text { Number of } \\
\text { Patients Achieving } \\
\text { Repigmentation }\end{array}$ \\
\hline EXCELLENT & $15(82 \%)$ \\
\hline GOOD & $2(12 \%)$ \\
\hline FAIR & - \\
\hline POOR & $1(6 \%)$ \\
\hline Table 2: Grading of Repigmentation
\end{tabular}

Overall clinical response was excellent among 82\% patients as shown in Table 2 .

\begin{tabular}{|c|c|c|c|c|c|}
\hline $\begin{array}{c}\text { Sl. } \\
\text { No. }\end{array}$ & $\begin{array}{c}\text { Site } \\
\text { Involved }\end{array}$ & $\begin{array}{c}\text { Number of } \\
\text { Patients }\end{array}$ & $\begin{array}{c}\text { Number of Lesions } \\
\text { Treated }\end{array}$ & $\begin{array}{c}\text { Lesions } \\
\text { Achieving } \mathbf{7 5 \%} \\
\text { Repigmentation }\end{array}$ & $\begin{array}{c}\text { Patients Achieving } \mathbf{7 5 \%} \\
\text { Repigmentation }\end{array}$ \\
\hline 1 & Lips & 7 & 17 & $16(94 \%)$ & $6(86 \%)$ \\
\hline 2 & Hands & 4 & 36 & $31(84 \%)$ & $4(100 \%)$ \\
\hline 3 & Feet & 7 & 38 & $30(79 \%)$ & $5(72 \%)$ \\
\hline TOTAL & \multicolumn{5}{|c|}{ Table 3: Distribution of Lesions and Number of Patients and Lesions Treated } \\
\hline \multicolumn{5}{|r}{}
\end{tabular}

Overall after split thickness skin grafting, lip responded better than hand and feet as shown in Table 3, probably it is due to good vascularity on the lip area, facilitate complete acceptance of graft and drug reaches adequate proportions in graft leading to significant clinical response.

Out of 18 patients with split thickness skin grafting, 2 (11\%) patients showed hyperpigmentation and 1 (6\%) showed hypertrophy.

Graft failure was seen in $1(6 \%)$ patient with split thickness skin grafting.
Clinical Photographs and Outcome of Surgery Patient 1

\section{Before Surgery}

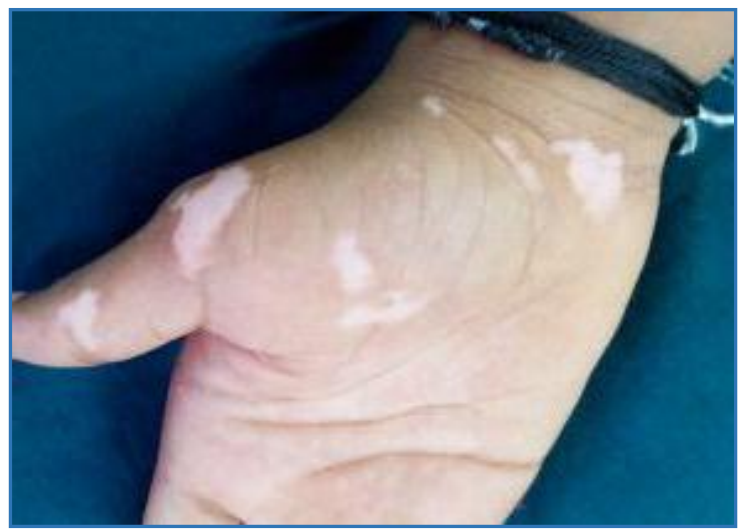

1 Week After Surgery 


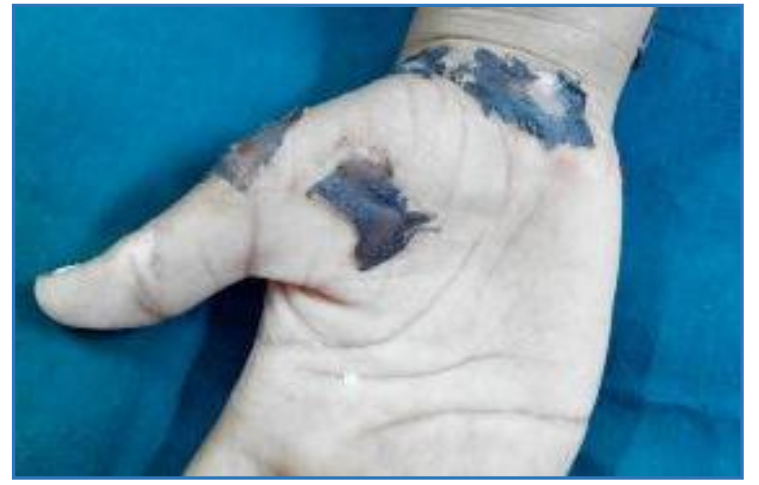

3 Months After Surgery

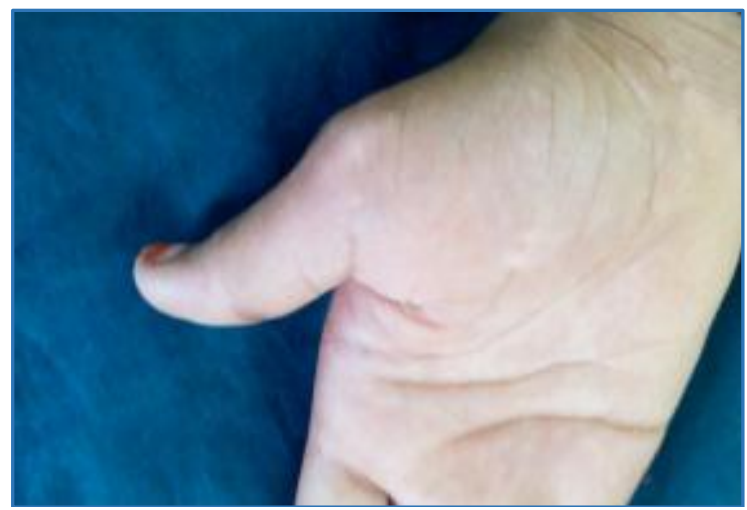

Patient 2

Before Surgery

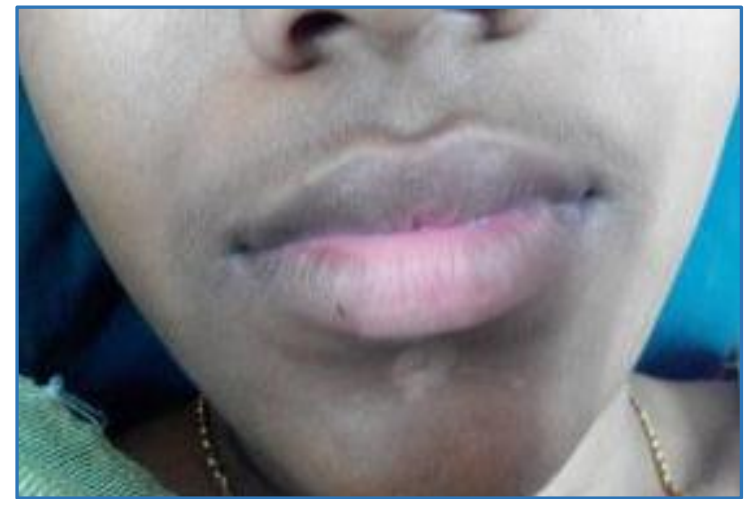

1 Week After Surgery

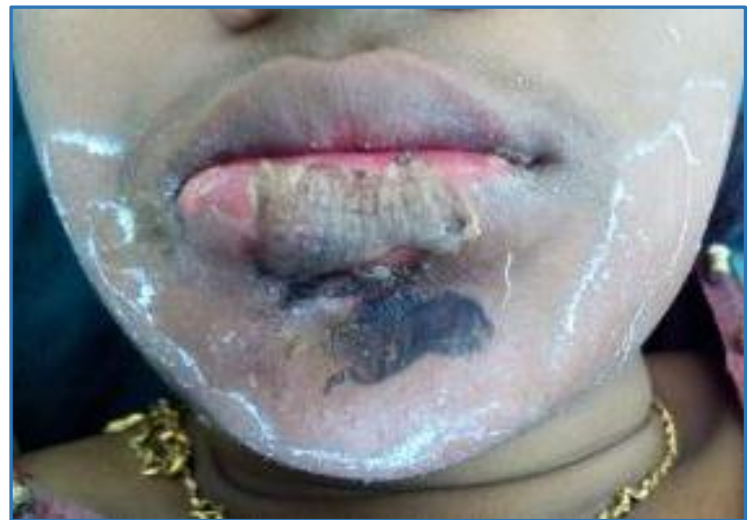

3 Months After Surgery

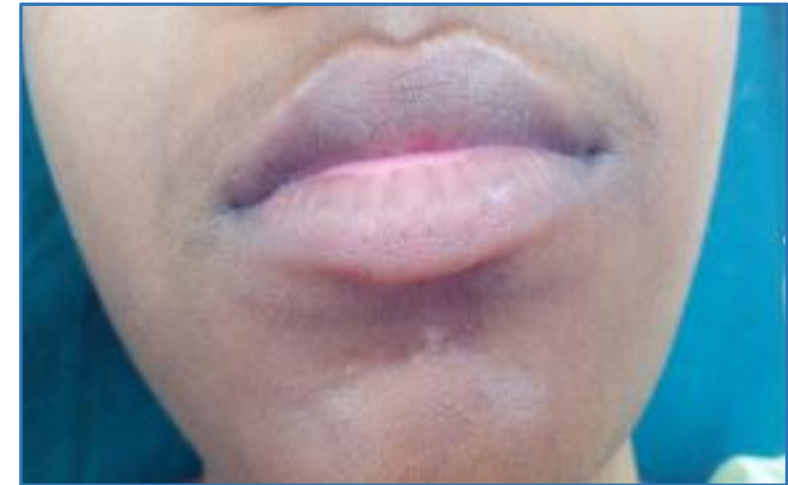

Patient 3

Before Surgery

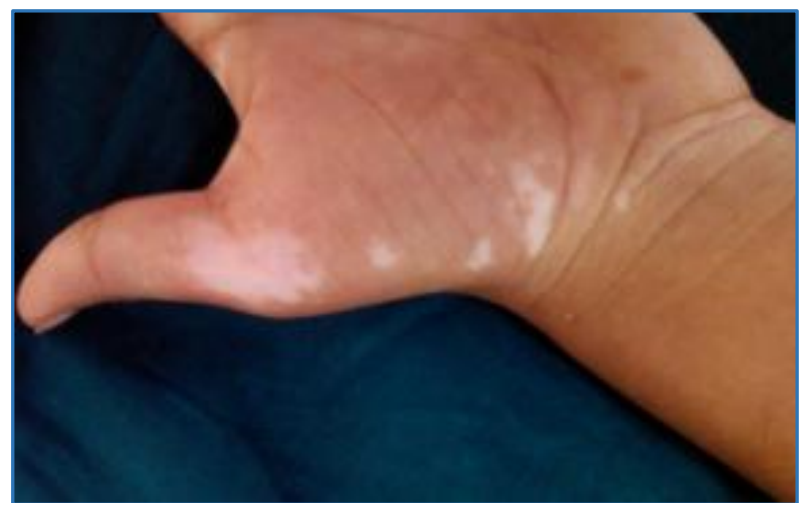

1 Week After Surgery

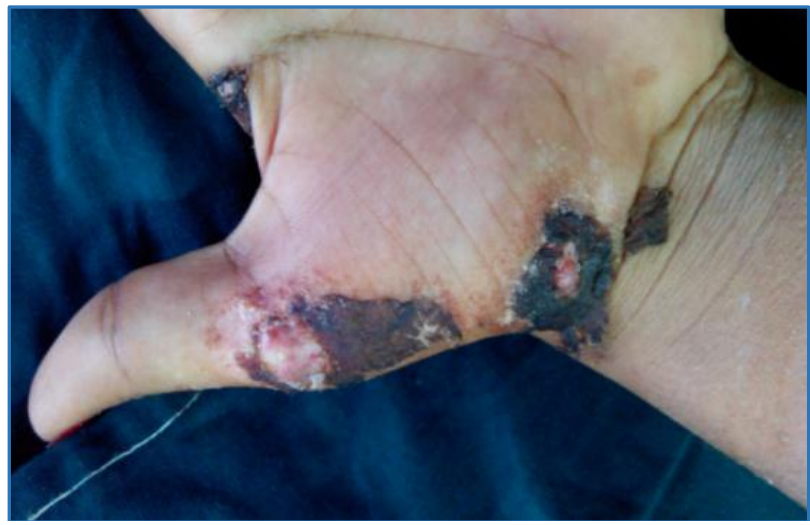

3 Months After Surgery

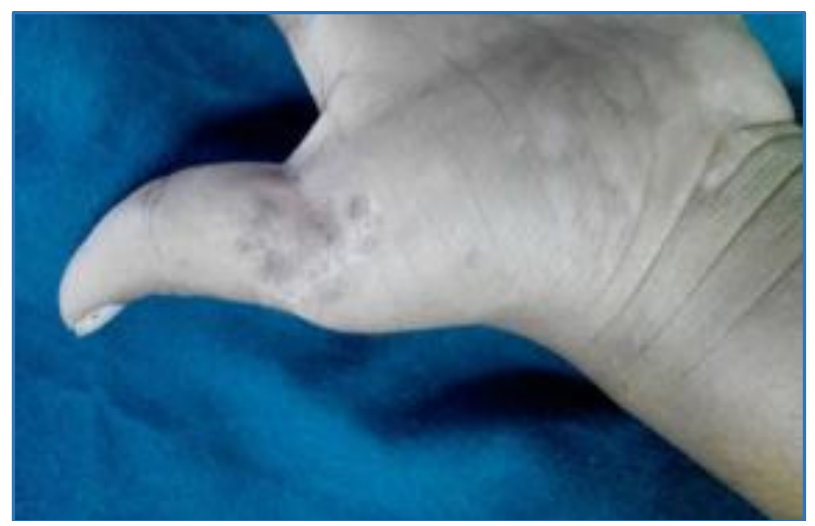

Patient 4 
Before Surgery

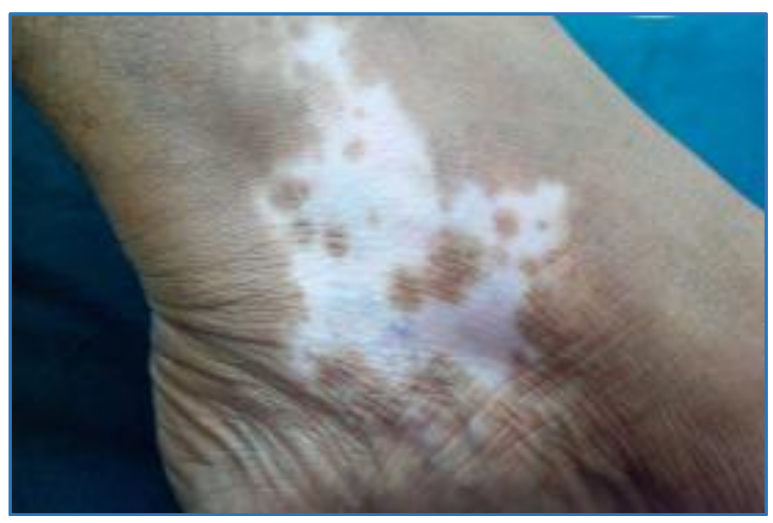

1 Week After Surgery

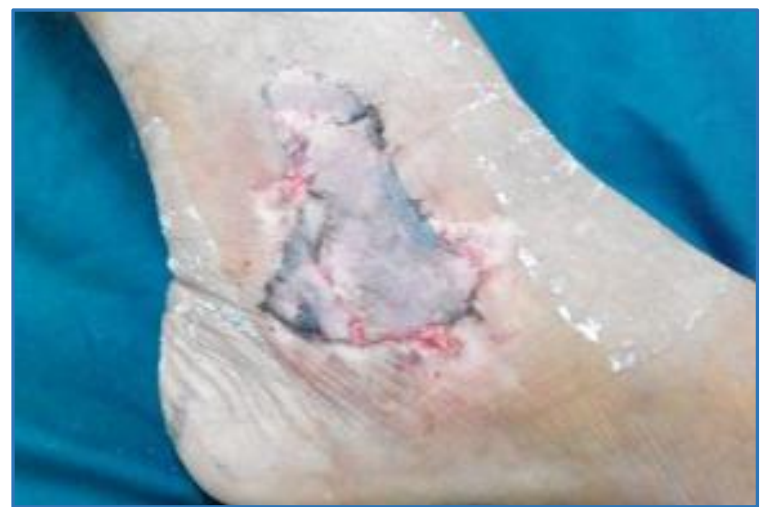

3 Months After Surgery

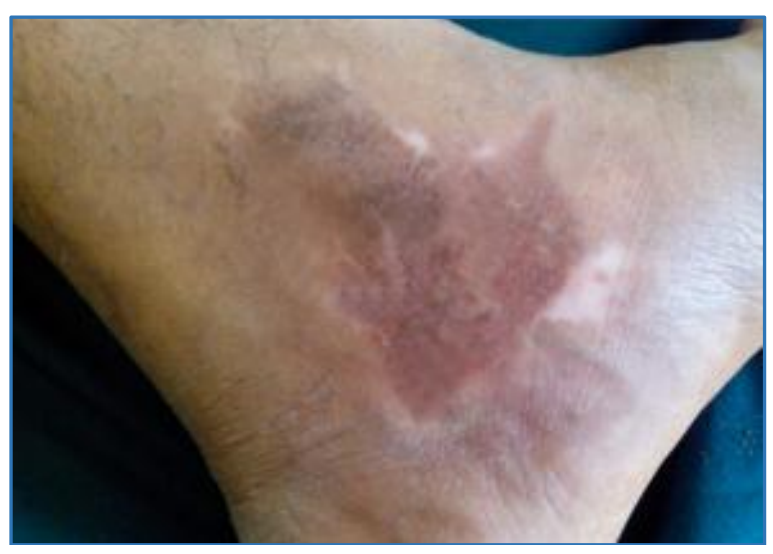

Patient 5

\section{Before Surgery}

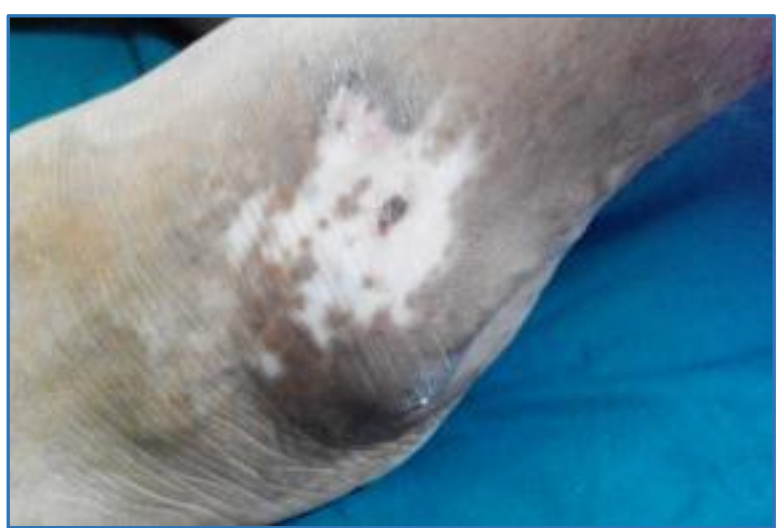

1 Week After Surgery

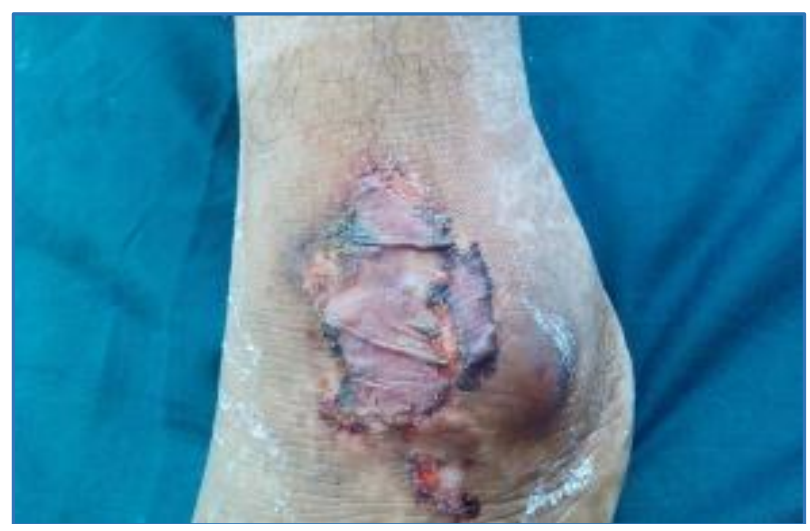

3 Months After Surgery

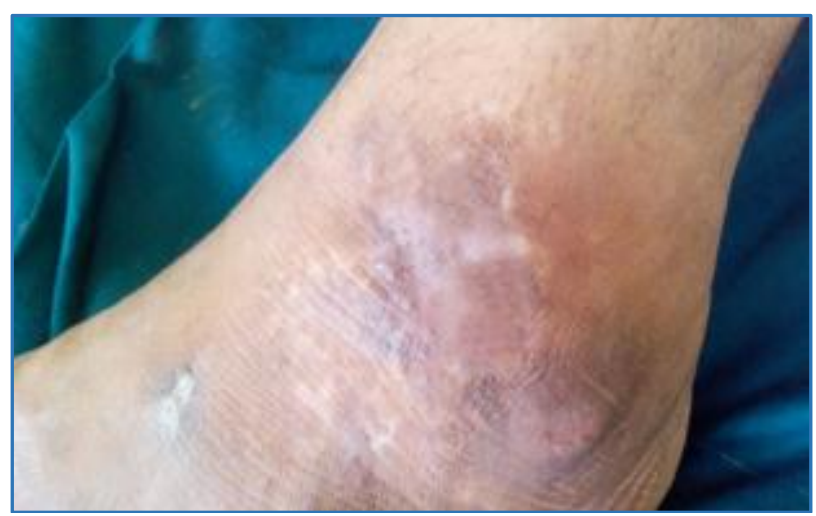

\section{DISCUSSION}

Vitiligo that is stabledefined as no progression of lesions already present, no fresh lesions and no evidence of Koebner phenomenon over at least 1 year.5It is present on non-hairy areas, does not respond to medical lines of treatment, can be managed by surgical modalities only. Surgical modalities broadly classified into tissue grafts and cellular grafts. Tissue grafts carry dermis and subcutaneous fat in addition to epidermis. The differentiation and development of the epidermal cells is regulated by the dermis. As far as tissue grafting procedures are concerned, there is a wide choice in the form of miniature punch grafting, suction blister grafting, split-thickness skin grafting and even follicular skin grafting. ${ }^{6}$ Each of these surgical techniques has its own advantages as well as disadvantages. In surgical technique like split thickness skin grafting, wherein a thin sheet of epidermis and part of papillary dermis is taken from an appropriate donor area and then transplanted on the dermabraded vitiligo lesion. This surgical treatment offers certain advantages over other tissue grafting procedures like mini punch grafting and suction blister grafting. 7

The cosmetic outcome achieved after split thickness skin grafting at the recipient as well as the donor site depend mostly on the quality of grafts taken. ${ }^{8}$ With ultrathin grafts having no accompanying dermal tissue, the quality of pigmentation achieved at the recipient site is usually excellent.9,10

Most of the patients in our study were between 20-30 years of age,which is the most productive age group, wherein the cosmetic disfigurement of vitiligo lesions play a major role. In this study, the most favourable response was also noticed in this age group. In present study, out of (18) 
patients (7) were male and (11) patients were female. As a level of awareness of cosmetic disfigurement, among females it is much higher. This study showed that it is true.

It was noticed that patient of the young age group, especially females who underwent treatment for patches on the exposed parts of the body responded better than others. Lesions on the lip which was treated showed good response in $(94 \%)$ of cases. Similarly, other exposed parts of the body that is hands, which were treated with split thickness skin grafting showed response in (84\%) of cases. These two areas which were grafted more frequently in the young age group patients showed better response than in other age group patients. Lesions on feet showed response in (79\%) cases, this was much lower than the first two areas mentioned above.

These were patients who responded better with treatment due to better compliance and regular followup.

Grafting procedures are supplemented with photochemotherapy to increase the chances of repigmentation as well as to achieve quicker results. PUVAsol is thought to have a proliferative as well as a stimulatory effect on the melanocytes donated through the grafting procedure. ${ }^{11,12}$ Thus one can achieve a rapid repigmentation when it is used as a supplementary therapy along with grafting procedure.Clinical studies have shown that in case of split thickness skin grafting, supplemental NBUVB not only causes a rapid repigmentation, but also minimizes the chances of perigraft depigmentation. ${ }^{13}$

In our study, $15(82 \%)$ out of 18 patients developed $>75 \%$ pigmentation with split thickness skin grafting. Over a period from November $1^{\text {st }} 2013$ to October 31 2015.

Khandpur et al. study, $25(83.3 \%)$ out of 32 cases developed $>75 \%$ pigmentation with split thickness grafting. Duration of study is over a period of one year. But this study is not specific for acral vitiligo;(18) cases were females and (14) cases were males; (2) cases showing hypertrophy and (1) case showed hyperpigmentation.

Imbran Majid et al. of study 20 (90\%) out of 22 cases developed $>75 \%$ pigmentation with split thickness grafting. Duration of study is over a period of one year; (12) cases were males and (10) cases were females; (1) case showed hyperpigmentation.

In our study, earliest response with split thickness skin grafting and PUVA sol therapy was noticed as early as one and a half month after grafting. One case only there was no significant response to split thickness skin grafting and PUVA sol therapy even after 9 months of completion of treatment.

\section{Factors Influencing Outcome of Vitiligo Surgery}

Thickness/Depth of the graft.

Graft margin area.

\section{CONCLUSION}

In a nut shell, surgical modality is the only option in managing resistant cases of vitiligo and can be recommended in the cosmetically conscious group between $20-40$ years' age group and discourage in people beyond 50 years to undergo this manoeuvre. Split-thickness skin grafting is claimed to be the most successful tissue-grafting procedure in acral vitiligo along with photochemotherapy.

It induces faster onset of repigmentation and it is technically more demanding and gives excellent colour match in terms of texture and cosmetic appearance, area of repigmentation in both donor and recipient sites with minimal complications. It can be done in any kind of setup with minimal equipment.

\section{REFERENCES}

1. Mattoo SK, Handa S, Kaur I, et al. Psychiatric morbidity in vitiligo: prevalence and correlates in India. J Eur Acad Dermatol Venereol 2002;16(6):573-8.

2. Aghaei $\mathrm{S}$, Sodaifi M, Jafari P, et al. DLQI scores in vitiligo: reliability and validity of the persian version. BMC Dermatol 2004;4:8.

3. Kovacs So. Vitiligo. J Am Acad Dermatol 1998;38(5Pt1):647-66.

4. Falabella R.Epidermal grafting: an original technique and its original application in achronic and granulating areas. Arch dermatol 1971;104(6):592-600.

5. Parsad D, Gupta S. Standard guidelines of care for vitiligo surgery. Indian J Dermatol Venereol Leprol 2008;74:S37-45.

6. Na GY, Seo SK, Choi SK. Single hair grafting for the treatment of vitiligo. J Am Acad Dermatol 1998;38(4):580-4.

7. Agrawal K, Agrawal A. Vitiligo: repigmentation with dermabrasion and thin split-thickness skin graft. Dermatol Surg 1995;21(4):295-300.

8. Suvanprakom P, Sompong DA, Pongsomboon C, et al. Melanocyte autologous grafting for treatment of leucoderma. J Am Acad Dermatol 1985;13(6):968-74.

9. Kahn AM, Cohen MJ. Repigmentation in vitiligo patientsmelancocytes transfer via ultra-thin grafts. Dermatol Surg 1998;24(3):365-7.

10. Achauer BM, Le Y, Vander Kam VM. Treatment of vitiligo with melanocytic grafting. Ann Plast Surg 1994;33(6):644-6.

11. Hann SK, Im S, Bong HW, et al. Treatment of stable vitiligo with autologous epidermal grafting and PUVA. J Am Acad Dermatol 1995;32(6):943-8.

12. Savant SS. Surgical therapy of vitiligo: current status. Indian J Dermatol Venereol Leprol 2005;71(5):307-10.

13. Khunger N, Kathuria SD, Ramesh V. Tissue grafts in vitiligo surgery-past, present, and future. Indian J Dermatol 2009;54(2):150-8. 